\title{
Memorias culinarias y representaciones tradicionales caracterizadas en la cultura ecuatoriana
}

\author{
Culinary memories and traditional representations characterized in the Ecuadorian \\ culture
}

Memórias culinárias e representações tradicionais caracterizadas na cultura equatoriana

ARTÍCULO DE REVISIÓN

Jessica Alexandra Robalino Vallejo

jrobalino@espoch.edu.ec

ORCID: 0000-0002-1464-5331

Ronald Mauricio Zurita Gallegos

ronald.zurita@espoch.edu.ec

ORCID: 0000-0001-8992-9008

\author{
Ana Matilde Moreno Guerra \\ amoreno_g@espoch.edu.ec \\ ORCID: 0000-0002-5807-8922
}

\section{Lilia Ofir Peralta Saá}

l_peralta@espoch.edu.ec

ORCID: 0000-0001-8958-8100

\section{Escuela Superior Politécnica de Chimborazo, Ecuador}

Recibido 12 de noviembre 2020 | Arbitrado y aceptado 23 de noviembre 2020 | Publicado en diciembre 2020

\section{RESUMEN}

El propósito de este artículo es registrar los saberes ancestrales al saber escondido entre los olores, sabores, texturas y tradiciones de las parroquias de Cacha y Flores, la cual pervive como una evidencia viva de la historia e identidad de los pueblos kichwa de la sierra centro en Ecuador. Para efectos de esta investigación, se adoptó el concepto establecido por la Convención para la Salvaguardia del Patrimonio Cultural Inmaterial UNESCO. El análisis de la información fue cualitativo, compilando historias, entrevistas y el ordenamiento territorial del Cantón Riobamba junto a las parroquias Rural Cacha y Rural Flores, con la finalidad de cumplir con el proceso de salvaguardar el patrimonio cultural e inmaterial de estos pueblos. Para finalizar, es importante destacar que la parroquia de Cacha se autodefine como Primera Parroquia Indígena en Ecuador, por lo que muchas de las prácticas y tradiciones que se mencionan sobre esta parroquia, no están presentes en Flores, que tiene otros sentidos de identidad y muchos de sus elementos culturales así como su autodefinición, están relacionados con el mestizaje.

Palabras clave: Memorias culinarias; patrimonio cultural inmaterial; saberes ancestrales; pueblos kichwa

\section{ABSTRACT}

The purpose of this article is to record the ancestral knowledge hidden among the smells, flavors, textures and traditions of the parishes of Cacha and Flores, which survives as a living evidence of the history and identity of the Kichwa peoples of the central highlands. in Ecuador. For the purposes of this research, the concept established by the Convention for the Safeguarding of the Intangible Cultural Heritage UNESCO was adopted. The analysis of the information was qualitative, compiling stories, interviews and the territorial ordering of the Riobamba Canton together with the Rural Cacha and Rural Flores parishes, in order to comply with the process of safeguarding the cultural and intangible heritage of these peoples. Finally, it is important to note that the parish of Cacha defines itself as the First Indigenous Parish in Ecuador, so many of the practices and traditions that are mentioned about this parish are not present in Flores, which has other identity senses and many of its cultural elements as well as its self-definition are related to miscegenation.

Key words: Culinary memories; intangible cultural heritage; ancestral knowledge; Kichwa peoples 


\section{RESUMO}

O objetivo deste artigo é registar o saber ancestral escondido entre os cheiros, sabores, texturas e tradições das freguesias de Cacha e Flores, que sobrevive como testemunho vivo da história e da identidade dos povos Kichwa do planalto central. Ecuador. Para os fins desta pesquisa, foi adotado o conceito estabelecido pela Convenção para a Salvaguarda do Patrimônio Cultural Imaterial da UNESCO. A análise da informação foi qualitativa, recolhendo histórias, entrevistas e ordenamento territorial do Cantão de Riobamba em conjunto com as freguesias Rural Cacha e Rural Flores, de forma a cumprir o processo de salvaguarda do património cultural e imaterial destes povos. Por último, é importante referir que uma freguesia da Cacha é definida como Primeira Freguesia Indígena do Equador, pelo facto de as muitas práticas e tradições que se referem nesta freguesia não estarem presentes nas Flores, que têm outros e muitos sentidos de identidade. Os elementos culturais, bem como a sua autodefinição, estão relacionados com a miscigenação.

Palavras-chave: Memórias culinárias; herança cultural intangível; conhecimento ancestral; Povos Kichwa

\section{INTRODUCCIÓN}

Es indudable la trascendencia de la alimentación, entendida como un hecho cultural. Comer no es solo una necesidad biológica sino también, una de las expresiones sustantivas más importantes de un complejo proceso cognitivo exclusivamente humano, de ordenamiento $\mathrm{y}$ asimilación del entorno natural y relacional.

Los comportamientos alimentarios de los seres humanos han sido moldeados y de alguna manera, determinados por un largo proceso de construcción de un saber colectivo que sobrepasa lo meramente alimentario y toma en cuenta facetas de carácter biológico, ecológico, tecnológico, social, político e ideológico (Contreras, 2008). Es por esto, que muchas comidas "significan" al ser consumidas, es decir, se preparan en relación con diversas fechas a las que se han asignado una fuerte carga simbólica, como la colada morada en el día de los difuntos, o la fanesca, en semana santa.

El hecho alimentario de esta manera, es una expresión creativa de la forma en que un grupo humano concreto, entiende su mundo y manifiesta su relación y vinculación simbiótica con el entorno en el que se desenvuelve. Con esta premisa, es posible asegurar que en los diversos platos y comidas están cocidos junto con los guisantes, papas o trozos de carne, innumerables contenidos simbólicos que en cada cucharada atan de manera irremediable a la historia y realidad social (Sánchez, 2015). Constituyen un elemento importante de la identidad de un colectivo.

De la misma manera, es posible aseverar como señala Delgado (2001) que la historia de cada sociedad, está articulada de manera profunda a un territorio concreto. El territorio se puede entender como paisajes que evocan recuerdos los cuales traen al presente sentimientos escondidos en la memoria pero también, es ese lugar físico en donde se encuentran arraigadas las costumbres, la historia, los valores y los referentes. El territorio también es cultura y aunque a veces se olvide, el territorio además constituye el conjunto de los alimentos que brotan de la tierra, los nutrientes que aportan al desarrollo humano, las formas $y$ combinaciones para llegar a ser parte del cuerpo, los significados asociados a ellas y las personas que los consumen y preparan en contextos concretos (Sánchez, 2015).

Sin embargo, es importante mencionar que las pautas de comportamiento $\mathrm{y}$ tradiciones alimentarias al igual que las culturas que las albergan, no son algo estático e inmutable. Frente a presiones externas 
muchos grupos humanos han reaccionado tratando de conservar sus tradiciones frente a otras extranjeras, o bien, acogiendo cambios radicales en sus patrones de alimentación. El actual contexto globalizado y las relaciones asimétricas entre diferentes poblaciones, los movimientos demográficos, las transformaciones de las condiciones sociales y económicas, las innovaciones tecnológicas, entre otros, han ido ejerciendo diversas presiones y en muchos casos están fomentando la pérdida de un conocimiento considerado patrimonial en muchos lugares.

Recetas que esconden este conocimiento se pierden paulatinamente, las cuales desaparecen con los ingredientes que las constituyen. El actual modelo de consumo ha hecho que muy pocos alimentos considerados más comerciales se produzcan en grandes cantidades, mientras que otras muchas variedades que no han calificado como mercancía rentable, pierden interés de ser cultivadas a tal punto que en los últimos cien años, han desaparecido el $75 \%$ de la diversidad agrícola con las consecuencias a nivel sanitario (desnutrición por falta de nutrientes adecuados), social y cultural que esto conlleva.

Cada vez la humanidad consume menos diversidad de alimentos, se nutre menos y pierde un poco de identidad. Por señalar un ejemplo, costumbres comunitarias como la "pampamesa" están en serio peligro, tanto como evidencia de la lógica redistributiva de la filosofía andina como práctica de cohesión social, de fortalecimiento comunitario y como pauta alimentaria y nutritiva. Hoy, como se señala más adelante en este trabajo, esta tradición en muchas comunidades está prácticamente abandonada.

El manuscrito permite un acercamiento al saber escondido entre los olores, sabores y texturas de la gastronomía de las parroquias de Cacha y Flores, la cual pervive como una evidencia viva de la historia e identidad de los pueblos kichwa de la sierra centro del Ecuador. Es importante considerar, que esta investigación tuvo la pretensión de registrar los saberes culinarios, aun cuando los actores sociales que entregaron la información, no relacionaron los alimentos con un sentido mítico, ritual o simbólico, sino que se refirieron a las preparaciones como formas aprendidas en su entorno, lo que se podría definir como procesos de enculturación, necesario como contribución cultural para el enriquecimiento de los saberes y sabores ancestrales referente de Ecuador, al mismo tiempo esta historia asiste en los procesos de formación pedagógica de estas regiones.

A lo largo del desarrollo del manuscrito se señalan rituales y tradiciones como elementos de identidad constitutivos de cada una de las parroquias estudiadas. En este sentido, cabe indicar los referentes teóricos que sustentan dichas definiciones son parte de cada representación cultural manifestada en Ecuador, en especial en las parroquias estudiadas.

Se entenderá como ritual, la parte manifiesta de una creencia, el acto denotativo en que está implícita la convicción de carácter religioso, que se ejecuta en tiempos específicos y que concreta un compromiso del individuo en su entorno cultural. Botero y Endara (2000) explican que un ritual puede definirse, como un tipo de manifestación donde se ejecutan actos religiosos, con la finalidad de orar, cantar canciones sagradas, danzar a los dioses, hacer sacrificios o preparar ofrendas. Se complementa con una ceremonia que abarca cierto número de rituales trabados y relacionados entre sí, realizados en algún tiempo determinado. Lo que lleva a reconocer al rito como el camino por donde se recorre la ceremonia, mientras que el ritual, complementa los pasos o la forma de recorrer ese camino. 
Existen variedad de ritos, tales como: de purificación, de sangre, de tránsito o de paso, funerarios, de iniciación, de conmemoración, entre otros. Unos tienen que ver con la pertenencia al grupo, a la familia o a la cultura, mientras otros con los cambios físicos, con los roles asignados dentro de la comunidad, así como con las relaciones entre la vida y la muerte. En fin, los ritos están asociados a los valores que la cultura establece como normas de convivencia (Giove, 2015).

Para definir la tradición, es necesario considerar que se diferencia de la costumbre por tratarse de una práctica que proviene de saberes de generaciones anteriores y que se establecen como formas de identidad, aunque en muchas ocasiones se realiza sin un sentido de pertenencia sino como un saber implícito en su comunidad. Al respecto, María Madrazo (2005) dice:

La tradición es un proceso de transmisión, que viene del pasado al presente, se realiza mediante una cadena de repeticiones que no son idénticas, sino que presentan cambios e innovaciones, y se van acumulando para crear lo que sería la gran tradición, un acervo reunido a lo largo de las repeticiones y que abarca las diferentes versiones de la tradición. (p.123)

Este estudio mantiene como propósitos principales mantener y preservar el patrimonio intangible en cuanto a su cultura ancestral, recetas culinarias, costumbres y manifestaciones, entre otros, importantes de los pueblos indígenas de la parroquia Cacha y Flores originarias de Ecuador.

\section{MÉTODO}

La metodología empleada radicó en un proyecto ejecutado sobre el registro de tradiciones Culinarias del cantón Riobamba, como parte de su Patrimonio Cultural Inmaterial, que buscó con ello, una expedición a gran escala cantonal para la salvaguardar las tradiciones, memorias y prácticas culinarias, así como de otros elementos culturales del cantón, bajo un convenio entre la Escuela Superior Politécnica de Chimborazo a través de su Escuela de Gastronomía, el Gobierno Autónomo Descentralizado Municipal del cantón Riobamba mediante su Dirección de Gestión Turística, la Casa de la Cultura Ecuatoriana, núcleo de Chimborazo y el Ministerio de Cultura y Patrimonio por intermedio de su Dirección Provincial en Chimborazo, autorizando la compilación e interpretaciones sobre las tradiciones que giran en torno al tiempo y a las identidades colectivas.

Para efectos de esta investigación, se adoptó el concepto establecido por la Convención para la Salvaguardia del Patrimonio Cultural Inmaterial (PCI) de la Organización de la Naciones Unidas para la Educación, Ciencia y Cultura (UNESCO) en el año 2003, según el Artículo Se entiende por "patrimonio cultural inmaterial" como los usos, representaciones, expresiones, conocimientos y técnicas -junto con los instrumentos, objetos, artefactos y espacios culturales que les son inherentes- que las comunidades, los grupos y en algunos casos los individuos reconozcan como parte integrante de su patrimonio cultural. Este patrimonio cultural inmaterial, que se transmite de generación en generación, es recreado constantemente por las comunidades y grupos en función de su entorno, su interacción con la naturaleza y su historia, infundiéndoles un sentimiento de identidad y continuidad $\mathrm{y}$ contribuyendo así, a promover el respeto de la diversidad cultural y la creatividad humana, (UNESCO, 2003).

Con puntos destacados dentro de los procesos de desarrollo del estudio se tomó en consideración únicamente que el patrimonio 
cultural inmaterial sea compatible con los instrumentos internacionales de derechos humanos existentes y con los imperativos de respeto mutuo entre comunidades, grupos e individuos y de desarrollo sostenible.

En función de la normativa vigente y de la metodología estructurada para su salvaguardia, las tradiciones, memorias y prácticas culinarias para esta concepción, forman parte del patrimonio cultural inmaterial al ser una serie de procedimientos culturales (conocimientos, técnicas y prácticas) que utilizan herramientas y productos específicos que las comunidades desarrollan para satisfacer las necesidades de alimentación de los seres humanos, en interacción directa con su entorno natural y vinculadas a su sistema de creencias.

En este estudio, el análisis de la información fue mediante la técnica cualitativa en donde se destacaron las historias de vida, entrevistas a informantes clave (tomando en cuenta, especialmente, la disposición de los participantes para colaborar con la investigación) y por último se realizó un análisis documental que permitió planes de ordenamiento territorial de las parroquias.

\section{RESULTADOS}

En este apartado, se destaca la información compilada de las historias, entrevistas y el ordenamiento territorial del Cantón Riobamba junto a las parroquias Rural Cacha y Rural Flores, con la finalidad de cumplir con el proceso de salvaguardar el patrimonio cultural e inmaterial de estos pueblos.

\section{El cantón Riobamba}

\section{Antecedentes}

La ciudad de Riobamba fundada por los españoles el 14 de agosto de 1534, es la cabecera del cantón del mismo nombre y capital de la provincia de Chimborazo. La ciudad se fundó sobre las ruinas de la ciudad destruida por Rumiñahui en su retirada hacia Quito, luego de la derrota de Tiocajas. El 4 de febrero de 1797 un terremoto destruyó la ciudad donde la colina de Cullca sepultó a gran parte de la ciudad, el fenómeno telúrico dejó miles de víctimas. (Paniagua, 1999).

Desde su fundación, el cantón Riobamba fue un conjunto de grandes haciendas reducidas hoy en su gran mayoría a minifundios destinados sobre todo a la economía de subsistencia que a la de acumulación. Declaró por primera vez su emancipación política el 11 de noviembre de 1820 como consecuencia de la cadena de declaraciones independentistas iniciada en Guayaquil el 9 de octubre del mismo año, y que pasó por Cuenca, Azogues y Guaranda. Aunque resultó ser un intento fallido, fue indispensable para consolidar el camino definitivo hacia la independencia nacional, que se concretó en Riobamba el 21 de abril de 1822 como antesala de la gloriosa Batalla del Pichincha, el 24 de mayo del mismo año. (Coronel, 2006).

La construcción del ferrocarril marcó un hito histórico en la vida del cantón, pues Riobamba no solo constituye un eje de comunicación para toda la región central del país, sino que, con esta propuesta de transporte, inicia una nueva dinámica comercial y de intercambio entre la costa y la sierra que generó también, un intercambio cultural en la región (Cepeda, 2003). A partir de la década de los años 60 con la Reforma Agraria, llega una nueva estructura productiva acompañada de una profunda transformación de las relaciones sociales y productivas. La tenencia de la tierra que estaba en manos de pocas familias, pasó a la forma de propiedad individual o comunitaria de los indígenas y las formas de producción 
sufrieron una indiscutible variación. Hasta la década de los años 80 , la base económica local fue la agropecuaria. En 1920 se formó por dicha circunstancia, la llamada Junta de Fomento Agrícola transformada en 1937 en el Centro Agrícola Cantonal de Riobamba. Desde 1931, el Centro Agrícola instituyó la Feria de Macají como una expresión de la producción local agropecuaria, cuyos mercados tradicionales siempre se localizaron en Quito, Cuenca y Guayaquil.

Actualmente, la presencia de las universidades locales, UNACH (Universidad Nacional de Chimborazo) y ESPOCH (Escuela Superior Politécnica de Chimborazo) marcan nuevas expectativas para la juventud del cantón y se presentan como una fuerte opción para los jóvenes que desean realizar sus estudios universitarios. Si bien la vocación productiva del cantón se orienta a lo agropecuario y ganadero, el comercio ha crecido en los últimos años y con mayor fuerza el comercio informal, provocando un desorden en la ciudad.

Otro sector con alto potencial es el turístico, el cual está vinculado al ferrocarril, naturaleza, cultura y centro histórico, por lo que se pueden generar procesos de desarrollo endógeno en el cantón. Ubicación.

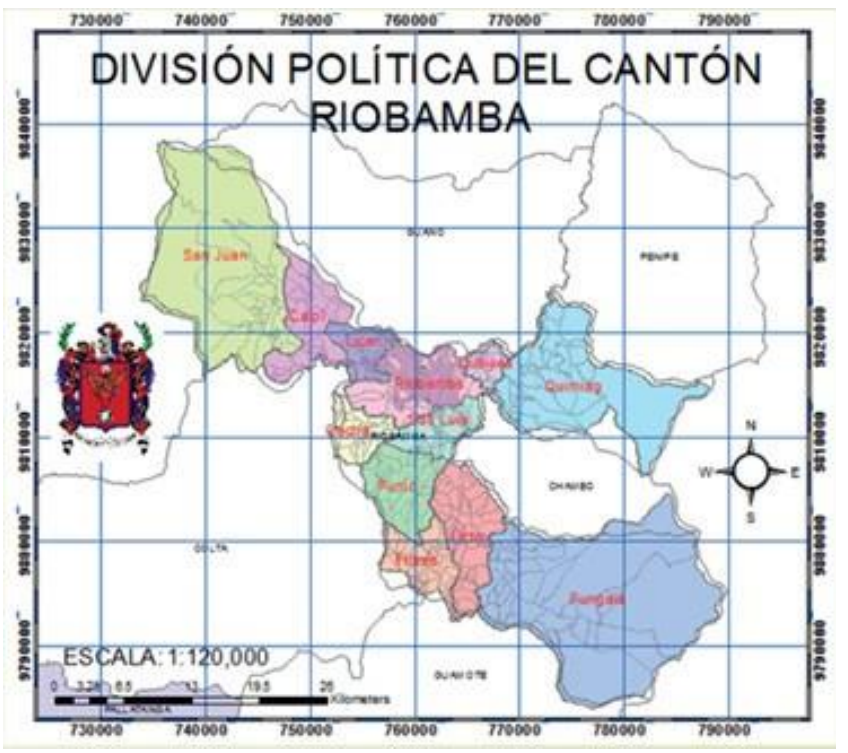

Figura 1. División política del Cantón Riobamba. (Fuente: PDOT Riobamba, 2015).

Como se indica en el Plan de Ordenamiento Territorial (PDOT) 2015, el cantón Riobamba

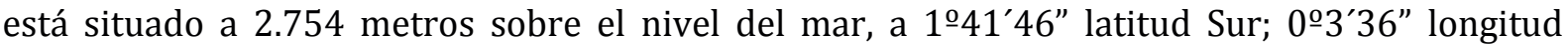
Occidental del meridiano de Quito. Se encuentra a $188 \mathrm{~km}$ al sur de la ciudad de Quito, en la región sierra central y es la capital de la provincia de Chimborazo.

- Norte: cantones de Guano y Penipe.

- Sur: cantones de Colta y Guamote.

- Este: cantón Chambo.

- Oeste: provincia de Bolívar. 


\section{División política}

El documento del Plan de Ordenamiento Territorial (PDOT) 2015, indica los siguientes datos sobre la ciudad de Riobamba: los nombres de las parroquias urbanas y rurales, la distribución de la población y la tasa demográfica.

De esta manera, Riobamba consta de cinco parroquias urbanas: Maldonado, Veloz, Lizarzaburu, Velasco y Yaruquíes; y de once parroquias rurales: San Juan, Licto, Calpi, Quimiag, Cacha, Flores, Punín, Cubijíes, Licán, San Luis y Pungalá.

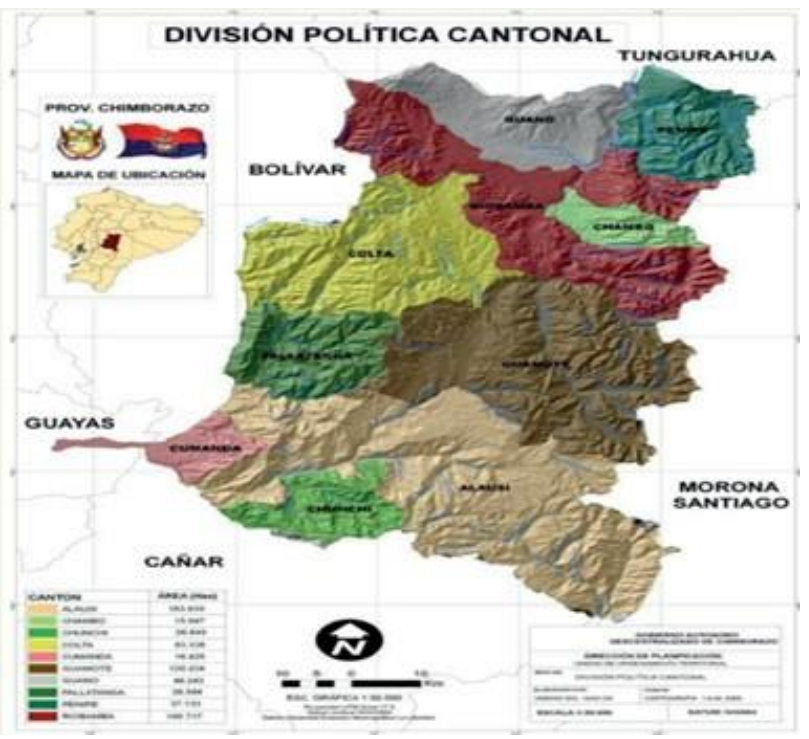

Figura 2. División política la provincia de Chimborazo. (Fuente: PDOT Riobamba, 2015).

\section{Calendario agro festivo}

La cosmovisión de los pueblos originarios se mantiene vigente a través de un gran número de saberes y conocimientos que permiten relacionarse con su entorno natural y social. De esta manera, la comunidad y las familias definen momentos para realizar sus actividades de sustento en la chacra, tales como la siembra y la cosecha.

Cada actividad tiene su momento y sus propios rituales que permiten pronosticar el clima de cada ciclo agrícola, donde el año está marcado por dos épocas: verano e invierno (época seca y época de lluvias).
El calendario agrofestivo en las comunidades indígenas, se refiere a los eventos tempo- espaciales de la Pacha Mama entrelazados y marcados por el caminar cíclico del sol en un lapso que se corresponde con lo que hoy conocemos como año. Cada ciclo, asocia e integra una diversidad de acontecimientos climáticos, agrícolas, ganaderos, astronómicos, festivos, rituales $y$ organizativos que se manifiestan en una secuencia de sucesos enlazados. 


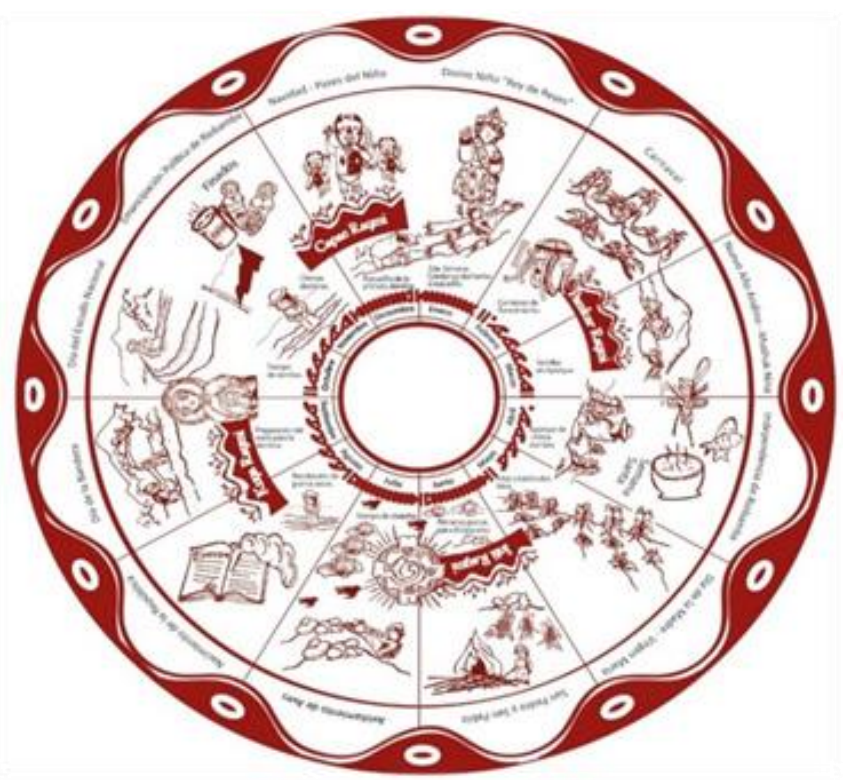

Figura 4. Calendario agro festivo. (Fuente: Dirección de Turismo GAD Municipal Riobamba, 2016).

Plantas medicinales utilizadas con frecuencia en las parroquias de Cacha y

\section{Flores}

El conocimiento popular sobre el uso de las plantas para aliviar distintas dolencias, es un saber que está presente principalmente entre las mujeres mayores. Si bien, existen personas especializadas en el uso de la medicina ancestral, también hay ciertas plantas que son de uso más común y son reconocidas fácilmente por la población en general. Este es el caso de las que se mencionan a continuación:

Taraxaco: utilizado para inflamaciones del útero, riñones e hígado. Para su preparación se coloca la planta en una piedra de río grande y plana, y se machaca con otra piedra de preferencia redonda. Para sacarle el zumo se pasa por un cedazo (colador). Se recomienda tomar este zumo tres veces al día (mañana, tarde y noche) por un lapso de ocho días. Las raíces de esta planta machacadas con hojas de malva o llantén cocinadas con linaza, sirven para hacer emplastos que se colocan sobre inflamaciones.

Santamaría, Marco y Ruda: las hojas de estas plantas se tuestan y calientan. Se aplican como emplasto sobre la zona afectada (articulaciones como rodillas o pantorrillas) de las personas que sufren dolores. Se cubre con un paño de lana negra, por la creencia de que el color negro mantiene el calor del cuerpo. Las semillas de estas plantas también se utilizan de la misma manera. Se recomienda que los emplastos sean aplicados durante las noches y que al día siguiente se deshaga del emplasto en una quebrada. Estas aplicaciones deben ser continuas hasta que calme el dolor (Guashpa, 2012).

\section{Parroquia Rural Cacha}

\section{Antecedentes}

En el Plan de Ordenamiento Territorial (PDOT) de la parroquia Cacha (2015), se cuenta la historia de esta población desde la época preincaica, haciendo énfasis en el imaginario colectivo sustentado en valores que le dan un sentido de identidad, a través de la recreación del mito de origen en el que se refuerza la idea de lo indígena como una forma de reconocimiento étnico que marca su pertenencia hacia la parroquia. En esta 
investigación, se asumió como definición de mito, una historia fantástica que remite al origen de un pueblo o de un conocimiento $y$ que se constituye, por lo tanto, es un referente de identidad.

De esta manera, Eliade (1991) manifiesta que:

El mito es una realidad, no es solo una imagen del pasado, sino un instrumento que el ser humano utiliza continuamente para percibir lo sagrado. Se adentra en las mitologías de la antigua Grecia, de los romanos, de los aborígenes de Australia, y relata un acontecimiento que ha tenido lugar en el tiempo primordial, el tiempo fabuloso de los “comienzos. (p.18)
Es así que en el PDOT (2015), la historia inicia con la presencia del Shiry XV (14631487) a quien en este documento se le llama rey, utilizando el mismo lenguaje occidental de la conquista. Luego hace una mención de los reyes Duchicela, que gobiernan en medio de varios enfrentamientos con diferentes pueblos hasta ser conquistados por el incario, siguiendo (como se indica en el documento) la versión del padre Juan deVelasco, en que se establece que la princesa Paccha Duchicela, hija de Cacha, sería una de las esposas de Huayna-Capac. De esta manera, en el Centro Turístico Pucará Tambo, se hace hincapié en el apellido Duchicela, como un elemento de gran trascendencia en la construcción de los elementos identitarios, aunque el lenguaje que se usa en forma reiterada usa términos como: linaje, raza, valentía.

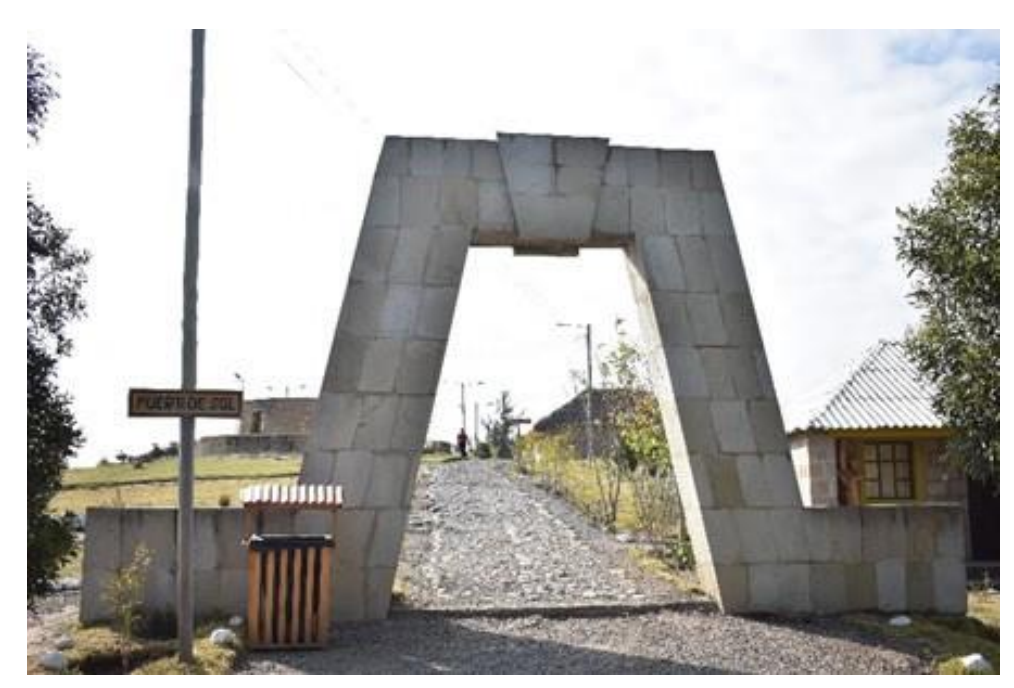

Figura 5. Entrada del sol, Centro Turístico y Cultural “Pucará Tambo”. (Fotografía: Bryan Agila, 2019).

En la reseña histórica del mencionado PDOT (2015), se indica:

La historia de Cacha se remonta a la era preincaica, carga de mitología, en la que, se dice, estas tierras estaban habitadas por una "raza superior de hombres", entre los que habían semidioses y seres sabios que eran hijos de la naturaleza, de los amores entre los dioses Chimborazo y Tungurahua. (p. 7). 
Aquí aparece otro elemento del mito, relacionado con la presencia de los volcanes como padres de la comunidad y al mismo tiempo, el sentido de superioridad frente a otros grupos étnicos, posiblemente en función reivindicatoria por efecto de la colonización y el sometimiento que ha ejercido la población blanca-mestiza a lo largo de los siglos. En este sentido, el pueblo Cacha tiene mucho apego a la referencia histórica de Fernando Daquilema, quien es descendiente de la familia Duchicela y constituye un ícono de las sublevaciones indígenas contra el sistema de hacienda, manifestado principalmente mediante el cobro del diezmo, en la presidencia de García Moreno, en 1871 (Costales, 1963). Se puede inferir que existen dos situaciones que ubican a Daquilema como símbolo Cacha: por un lado, el hecho de haber sido coronado como Rey Cacha luego de la matanza al cobrador de diezmos Rudecindo Ribera; y, por otro, su trágico fin al haber sido fusilado. Esto lo perfila como un héroe que marca un ideal de valentía y fortaleza.

Cacha, fue inaugurada como parroquia civil el 25 de abril de 1981 por el Presidente de la República del Ecuador, Ab. Jaime Roldós Aguilera. Esta declaratoria es de mucha importancia para la parroquia, lo que le ha permitido contar con una dinámica socio organizativa autónoma, hasta la actualidad (PDOT, 2015).

\section{Composición étnica}

Según la información del PDOT (2015) en la parroquia de Cacha, el 100\% de la población de las 19 comunidades se autodefine como indígena, de las cuales el 89,47\% hablan kichwa y español, mientras que el 10,53\% hablan solamente kichwa.

\section{Indumentaria del pueblo Puruwá}

Tambo es una de las 23 comunidades que conforman la Parroquia Cacha y la familia
Duchicela es quien brinda el debido mantenimiento al centro. Para efectos de la investigación, se ha realizado una entrevista a profundidad a Luz León (2018), encargada de proporcionar la información en el Centro Comunal Pucará, de la cual se extraen sus principales apreciaciones a continuación.

Según la entrevistada, la vestimenta del pueblo Puruwá tiene un sentido y significado respecto a sus actividades, creencias y orígenes. La vestimenta de los hombres está conformada por el poncho, sombrero blanco, una faja con diseños (cagüiña) y pantalón blanco de basta ancha. Para las mujeres, la vestimenta consta de: sombrero blanco, chalina, shigra, tres fajas: una faja pequeña, la mamachumbi y la faja de Cacha, camisón largo, anaco, bayeta de lana de borrego, guango y accesorios: orejeras y el collar. (Figura 6, A, B, C y Figura 7, A, B, C).

Luz León señala que, si bien el sombrero fue una imposición de la colonia española, los habitantes actualmente le atribuyen a este, la capacidad de proteger la inteligencia de un hombre o una mujer, por lo que es muy importante que siempre lo lleven puesto. Alrededor del sombrero tiene una faja con diseños tejidos que hacen alusión a las festividades, como por ejemplo: las chacras, el Inti Raimi, agradecimientos a la Pacha Mama y las cosechas que se celebran en la comunidad. El poncho que comúnmente se usa hasta hoy, es de lana de borrego teñido con un entramado que da el diseño de la chacana (elemento simbólico de múltiples significados, entre otros, la presencia de las estaciones del año y la relación entre lo humano y lo divino). De igual forma, para los habitantes de Cacha, el color rojo usado en el poncho, representa la sangre, el coraje, la fuerza, la valentía del pueblo Puruwá. 

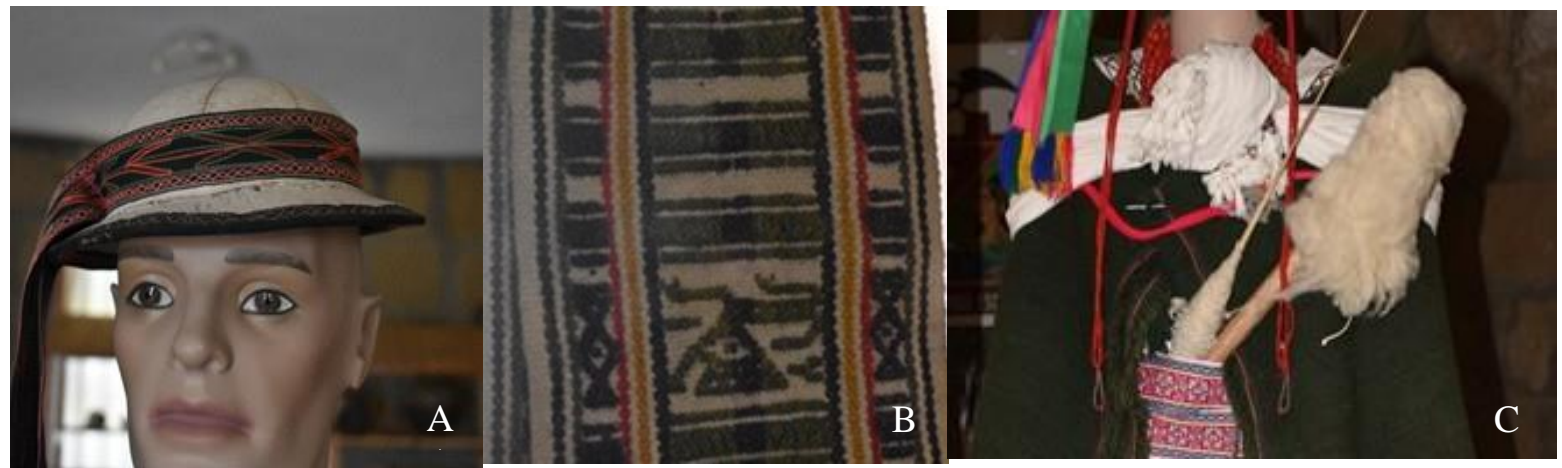

Figura 6. A. Sombrero de hombres. B. Faja. C. Guango. (Fotografía: Bryan Agila, 2019 Fuente: Centro Comunal, Centro Turístico y Cultural “Pucará Tambo).

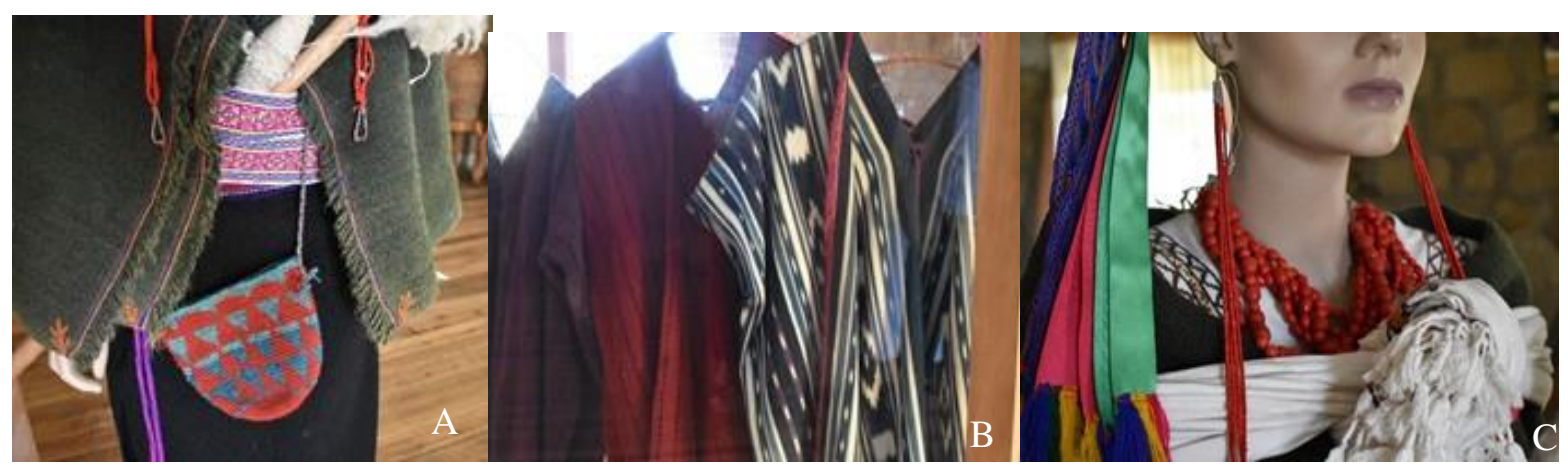

Figura 7. A. Shigra. B. Ponchos de Cacha. C. Collar y pendientes de la mujer indígena. (Fotografía: Bryan Agila, 2019 Fuente: Centro Turístico y Cultural “Pucará, Tambo”).

\section{Mercados, espacios de comercialización de alimentos}

La feria de Cacha se distingue por la presencia de variados objetos y manufactura de coloridos ponchos. Cada año se realiza la feria y la fiesta de la nacionalidad con la presencia de los representantes de todas las comunidades. Los tejidos son de gran valor comercial, tanto las bayetas como los ponchos, bolsos y sombreros, entre otros artículos. Los días sábados se venden estos productos en la feria de la Concepción de la ciudad de Riobamba. (Figura 8)

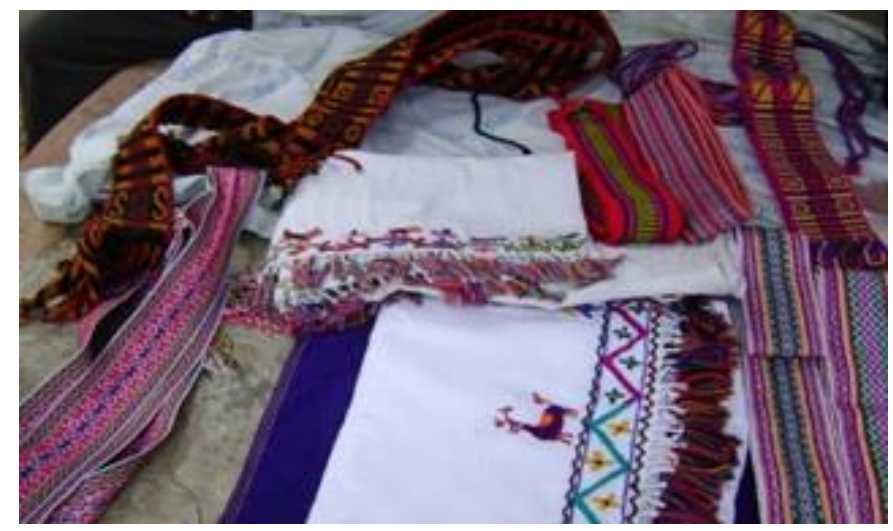

Figura 8. Feria cultural de Cacha. (Fuente: GAD Parroquial de Cacha, 2019) 


\section{Lugares emblemáticos de la parroquia}

\section{Centro turístico y cultural "Pucará Tambo"}

Este es un centro turístico comunitario que representa a 23 comunidades de la parroquia, que cuenta con un museo sobre la cultura Cacha, una plaza ceremonial, un restaurante y cabañas para alojamiento de turistas. Pucará Tambo significa "lugar de descanso y sitio desde donde se ve". En este Centro se realizan recreaciones de las principales ceremonias indígenas en las fechas relacionadas con las celebraciones de la siembra, el florecimiento y la cosecha, con el propósito de difundir la cosmovisión de la cultura Puruhá.

\section{Iglesia de Cacha (1979)}

Es una iglesia católica construida con material propio de la zona, una roca volcánica denominada "cangahua" en forma de bloques. Las paredes tienen un grosor de un metro, aproximadamente. Además, tiene una puerta de madera tallada por los mismos pobladores de la parroquia. El techo está cubierto de teja y descansa sobre una base de carrizo, chaguarquero (tallo que emerge del centro de la cabuya) y estera, mientras la puerta es de madera. (Figura).

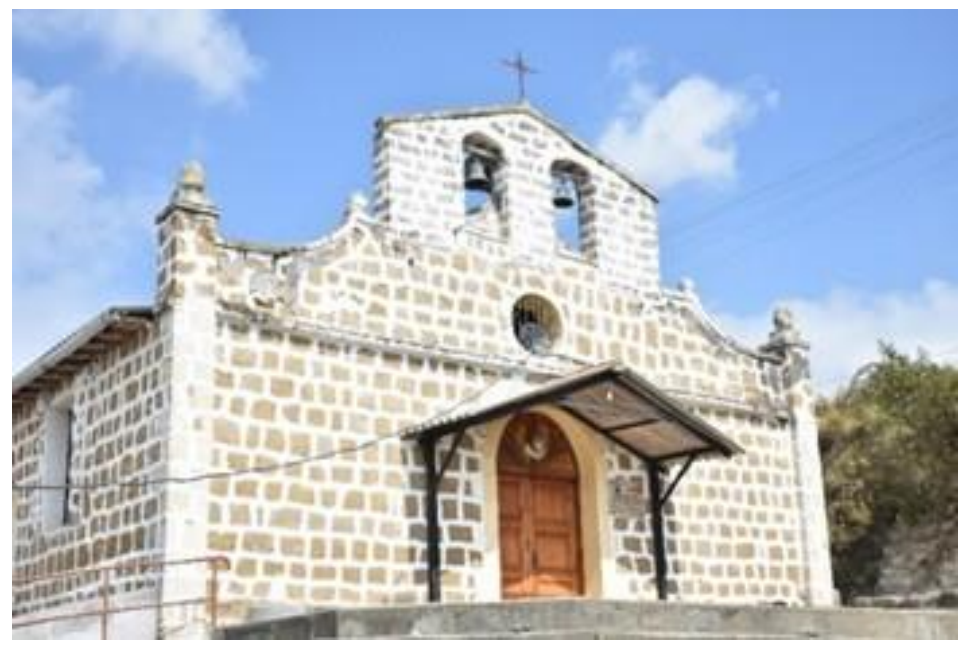

Figura 9. Iglesia de Cacha. (Fotografía: Bryan Agila, 2019).

\section{Prácticas comunitarias tradicionales}

Para esta investigación, se entiende como prácticas comunitarias tradicionales al conjunto de actividades que se realizan en comunidad y que tienen significaciones específicas dentro del propio grupo, en el que están implícitas diversas expresiones del saber y de la convivencia que reflejan el carácter ordinario y el extraordinario de su quehacer. Al respecto, González (2015) dice: "Las prácticas culturales son construcciones colectivas que incluyen formas de expresión y participación que son parte de la cultura." (p. 11).

En Cacha, las prácticas todavía existentes de las que la población hace referencia, son: la minka, el prestamanos y la jocha. Las dos primeras tienen que ver con los tiempos ordinarios, es decir, con la vida cotidiana, el trabajo, la sobrevivencia. La diferencia que se encontró en esta investigación entre la minka y el prestamanos, es que la minka tiene relación con las actividades que benefician a la comunidad en general, mientras que el 
prestamanos, es una colaboración de la comunidad en actividades que benefician a una familia en particular y que conlleva una retribución posterior. Por su parte, la jocha corresponde a los tiempos extraordinarios, es decir los festivos. La pambamesa tiene características muy específicas, que se indicarán más adelante. Adicionalmente se tienes algunos otros emblemáticos en la parroquia como: Rumi wasi; Ruinas de la casa de Fernando Daquilema, Ruinas de la casa de Fernando Daquilema (El Centro Cultural "Pucará Tambo"), en este lugar practican la técnica del tejidos de sus indumentarias como el Telar de pedales, Telares de cintura, Teñido del poncho coco con la técnica Ikat, Tejido del poncho de Cacha, Proceso del tejido. (Figura 10).

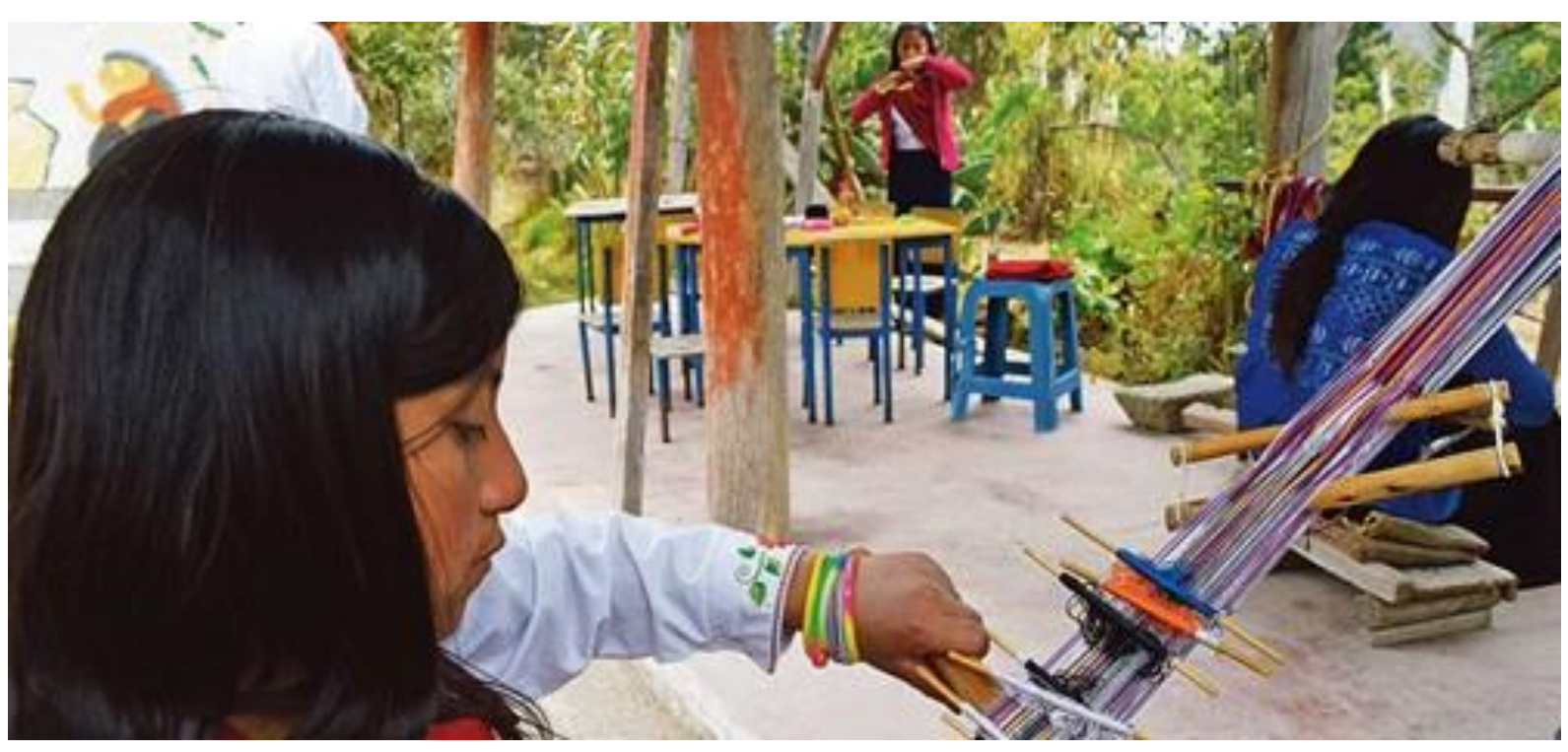

Figura 10. Técnicas de hilado y tejido de Cacha. (Fuente: Elizabeth Maggi / El Telégrafo, 2015).

\section{Prácticas comunitarias tradicionales}

Para esta investigación, se entiende como prácticas comunitarias tradicionales al conjunto de actividades que se realizan en comunidad y que tienen significaciones específicas dentro del propio grupo, en el que están implícitas diversas expresiones del saber y de la convivencia que reflejan el carácter ordinario y el extraordinario de su quehacer. Al respecto, González (2015) dice: "Las prácticas culturales son construcciones colectivas que incluyen formas de expresión y participación que son parte de la cultura." (p. 11).

En Cacha, las prácticas todavía existentes de las que la población hace referencia, son: la minka, el prestamanos y la jocha. Las dos primeras tienen que ver con los tiempos ordinarios, es decir, con la vida cotidiana, el trabajo, a sobrevivencia. La diferencia que se encontró en esta investigación entre la minka y el prestamanos, es que la minka tiene relación con las actividades que benefician a la comunidad en general, mientras que el prestamanos, es una colaboración de la comunidad en actividades que benefician a una familia en particular y que conlleva una retribución posterior. Por su parte, la jocha corresponde a los tiempos extraordinarios, es decir los festivos. La pambamesa tiene 
características muy específicas, que se indicarán más adelante.

\section{Preparaciones culinarias}

\section{Gastronomía festiva}

La preparación de la gastronomía festiva tiene una connotación ritual y comunitaria, debido a que desde los instrumentos utilizados hasta la preparación de las recetas son diferentes a los de la gastronomía cotidiana. Por ejemplo, el cuy con papas es un plato que se sirve de manera especial para celebraciones de la parroquia y sus comunidades, en el caso de matrimonios, bautizos y por supuesto el carnaval y Pawkar Raymi.

En el Pucará Tambo al final de la celebración del Pawkar Raymi, se realiza una ofrenda de: cuy con papas, panes, queso, mote y bebida de chicha, como comida comunitaria.

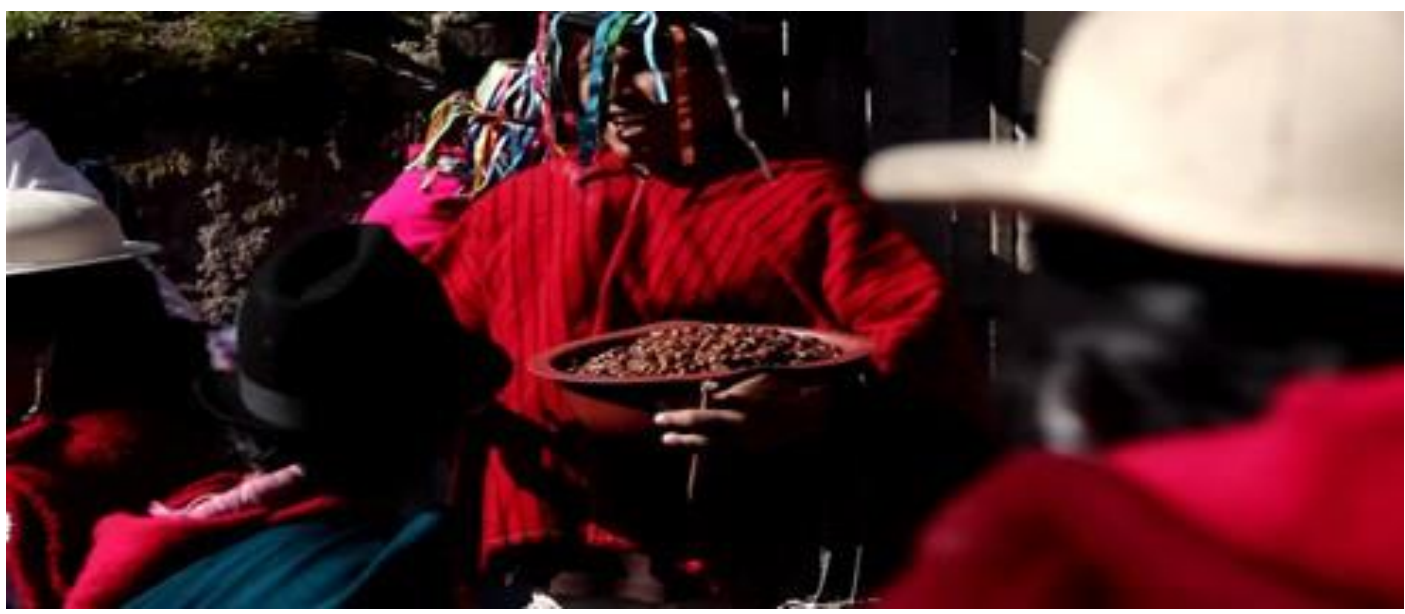

Figura 11. Gastronomía con la comunidad

María Agustina Asqui (2016), habitante de Cacha, comenta que "Para las fiestas de carnaval se prepara la chicha y el mote pelado junto con carne de chancho, el cual compran o pelan, así también con papas peladas y mote. Las personas llevaban banderas con las cuales iban de casa en casa, de loma a loma, pero hoy en día ya no lo hacen, iban bailando algunos tomados de las manos".

Por su parte, Alberto Llangarí (2016) habitante de Cacha, mencionó: "Apenas llegamos a la fiesta nos dan una bebida mezclada entre chicha y trago, diciendo que es un aperitivo; y luego nos sirven primero caldo con mote, cuero de chancho o carne de borrego así, luego reparten un plato de mote a cada una de las personas presentes. Después los priostes entregan como presentes dos barriles de chicha al fundador, a esos barriles de chicha agregan varios litros de trago tomando esa mezcla, diciendo que con eso no sentían hambre y andábamos no más".

\section{Bebidas tradicionales}

En la mayoría de localidades de la región, los indígenas acostumbran beber chicha, sea para establecer un compromiso de compadrazgo, festejar las cosechas, realizar un matrimonio o conmemorar la fiesta del Carnaval o de algún santo. (Figura 12). 


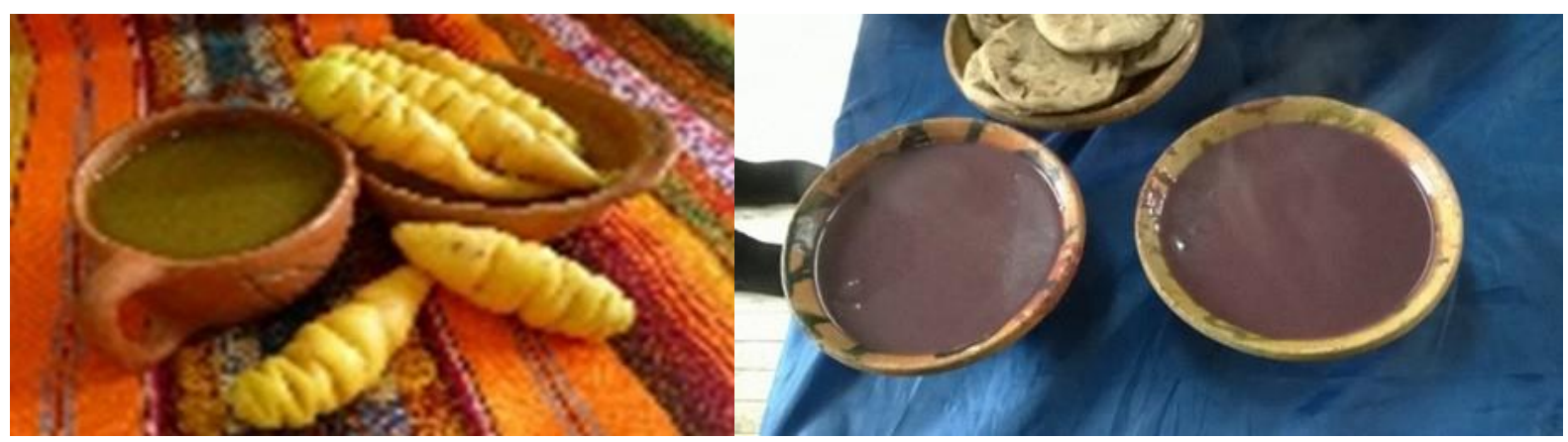

Figura 12. A. Dulce de mashua. (Fotografía: Esthefanny Sánchez, 2018). B. Colada morada.

Esta parroquia cuenta con una amplia gastronomía en la que destacan el Jucho, papa ucho, caldo de gallina Maki uchu (ají macho), Locro de oca, Locro de melloco, Cucayo (Tonga), Máchica, arroz de cebada. La descripción de cada uno de estos platos se encuentra plasmados en la investigación que llevaron a cabo los autores. Allí se encuentran los recetarios y modos de preparación de cada uno de los platos que se mencionan.

\section{Artefactos y usos}

En la actualidad, la parroquia de Cacha practica la agricultura de subsistencia, ya que la mayor parte de la producción se destina para el autoconsumo. En la preparación del suelo se emplea un tractor, yunta y/o azadón, el abono orgánico proveniente de las especies menores, se usan plaguicidas sin asesoramiento técnico. Cada una de las comunidades tiene claramente definidos los tiempos de siembra, deshierba y descanso.

El empleo de cucharas de palo, piedras de moler, ollas de barro, pailas, planchas de piedra y hornos de leña para la fabricación de platos tradicionales, es todavía frecuente entre los habitantes de Cacha, pese a la introducción de productos industriales. "Antes cocinábamos solo con leña, paja, con el tallo de las habas, tallo de la quinua, con eso cocinábamos, en esas épocas no había muchos árboles." (A. Llangarí, comunicación personal del 26 de julio de 2016). A continuación se mencionan los artefactos más utilizados:

Cuenca plato. Lleno de mote, papas, cuy y gallina, se entrega al novio y al padrino quienes debían comer toda la comida para augurar felicidad del matrimonio. La cuenca plato mediano es para la novia. Batea. Es una bandeja que sirve para moler la máchica llamado maki máchica. Kisita. Olla para mantener la sal en buen estado. Washa. Jarra para el agua. Cuchara mama. Para cocinar en pailas y ollas grandes o para repartir sopa en los platos. Achiotero. Recipiente para colocar el achiote con manteca o aceite y calentarlo al fuego. Humerito. Para quemar el saumerio "shaumar". Aysana manga pequeña. Recipiente para transportar el desayuno. Aysana manga mediana. Recipiente utilizado para "llevar la colada morada a las almitas en el panteón". (M. Asqui, comunicación personal del 28 de julio de 2016). Aysana manga grande. Recipiente para llevar el caldo a los taitas y mamas en el saludo de finados. Se tapa con una cuenca plato para que el caldo no se enfríe. El "mangahuato". Es el cordón de cuero o de cabuya, si es de cuero es de la res, curtido con sal y manteca de gallina. Manguita. Olla de barro para guardar la manteca. Se la elabora en Cacha Panadero con tierra negra del Cerro Chuyug, entre otros artefactos. 


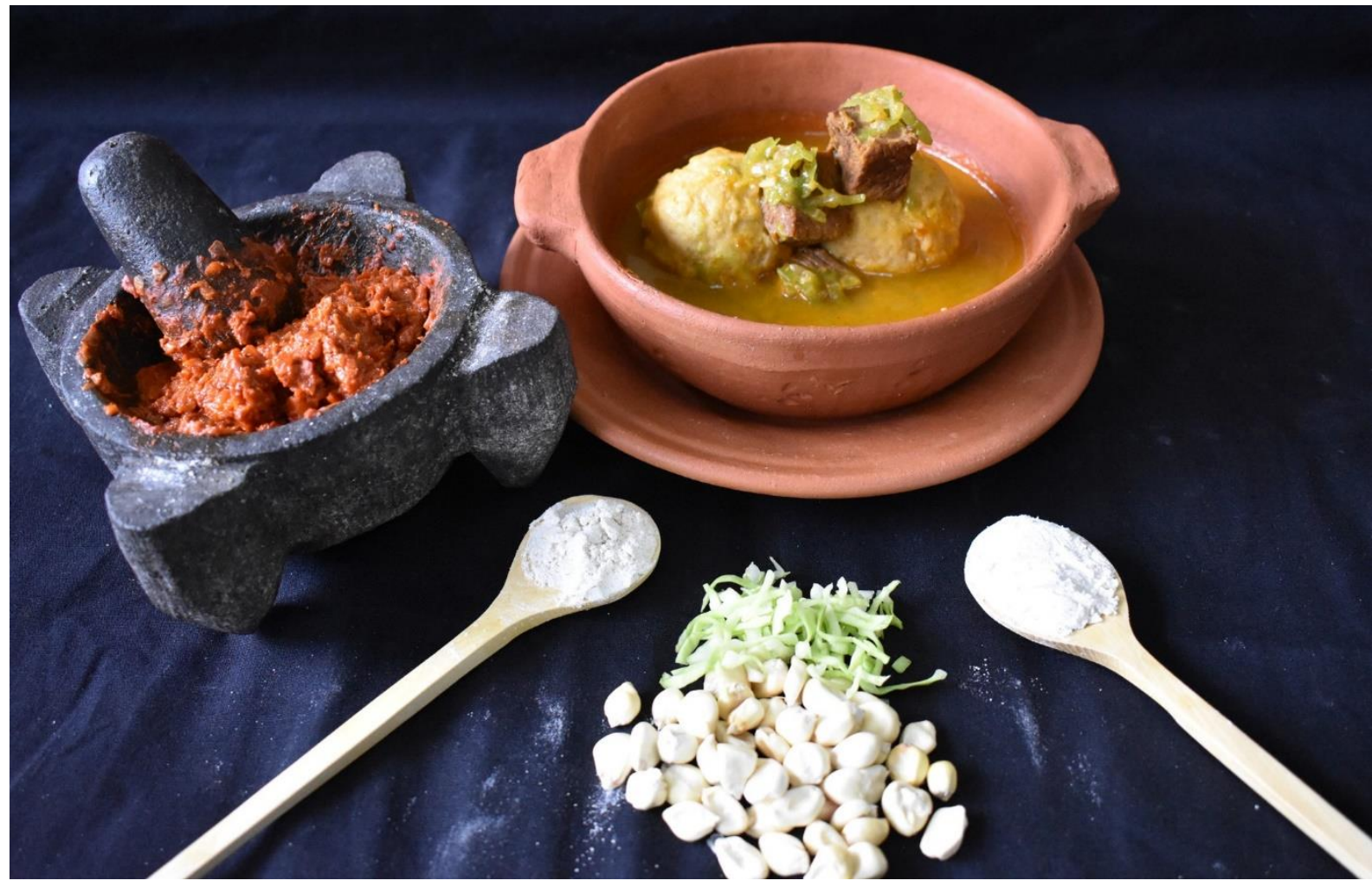

Figura 13. Utensilios de cocina.

\section{Parroquia Rural Flores}

El PDOT del GAD Parroquial (2015) indica que la parroquia de Flores lleva su nombre en honor a José Flores, personaje dueño de los caseríos del lugar hasta aproximadamente inicios del siglo XX (1900). Posteriormente en el año de 1919, según el Registro Oficial No. 713 en la presidencia del Dr. Alfredo Baquerizo Moreno, los pobladores lograron la creación de la parroquia Flores con seis caseríos denominados: Caliata, Santa Rosa, Naubug, Gompuene, Basquitay y Puesetus. Abdicaron de pertenecer a la nueva parroquia, los ayllus Guempuenes, Obrajes y Nabus Loma, hoy conocidos como Naubug y Guantul. Otros caseríos siguieron perteneciendo a las jurisdicciones de las parroquias de Licto (Pisitus- Pillishs), Punín (Real Corona) y otros al cantón Guamote.
Las tierras fueron adquiridas a inicios del siglo XX por las familias hacendadas vinculadas a los apellidos Chiriboga, Baldeón entre otros. Desde entonces, la mayoría de las tierras de las zonas media y alta de la parroquia fueron propiedad de las familias que habitaban en las cabeceras parroquiales de Flores y Licto. Con el pasar del tiempo, las propiedades fueron enajenándose hasta que llegaron a manos de los indígenas (PDOT, Flores, 2015).

\section{Composición étnica}

El PDOT del GAD Parroquial (2015) indica que "La composición étnica de la parroquia, mayoritariamente indígena kichwa hablante, constituye el 99\% del total" (p. 52). Hace referencia también al censo del INEC (2010) en el que se establece que el 98,70\% 
de la población se autodenomina indígena, el $1.06 \%$ mestiza, el $0,11 \%$ blanca, el $0,02 \%$ negra, y otros el $0,11 \%$.

El PDOT (2015) hace referencia sobre las "características socio culturales, que configuran a Flores como un conjunto comunitario homogéneo en sus comportamientos" (p. 56), también menciona a los flujos migratorios, que inciden en cambios culturales y étnicos con el paso del tiempo. (Figura 14).

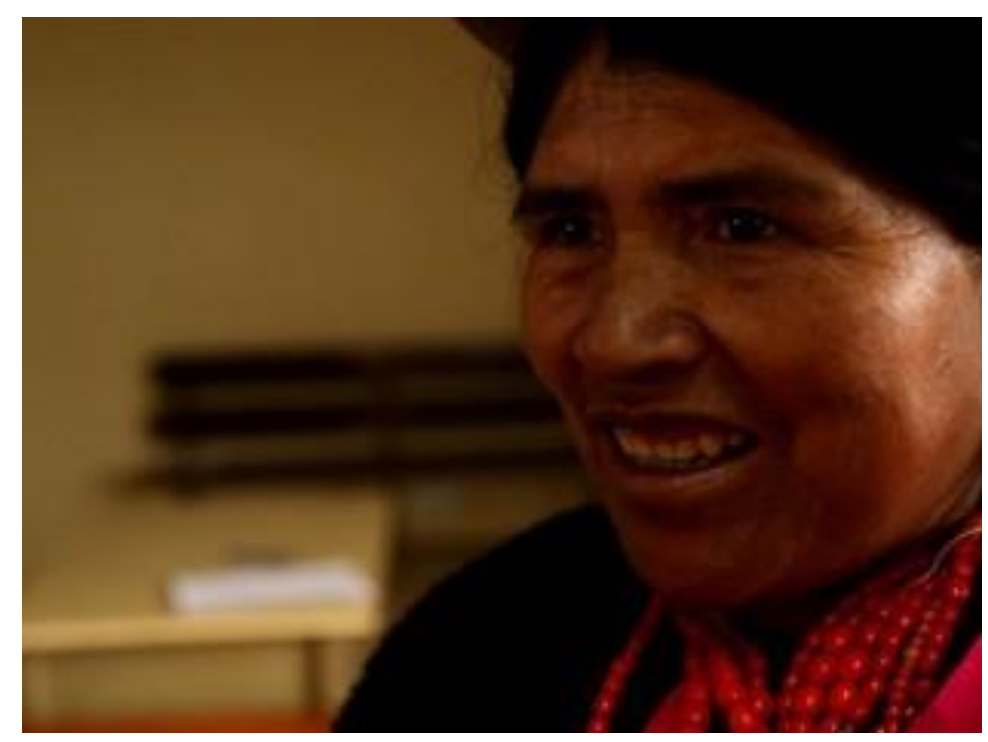

Figura 14. Habitante de Flores. (Fotografía: Javier Aucancela, 2016).

\section{Vestimenta}

Anacleto Pucuna, habitante de Flores, describe la vestimenta tradicional de los hombres de la zona alta de la parroquia, que incluye: un poncho de lana de borrego, con rayas azules o negras, el tejido es liviano. En la zona baja, los ponchos también son de lana de borrego de color rojo. Indica que actualmente utilizan estos ponchos solo para festividades $\mathrm{u}$ ocasiones especiales, por motivos de comodidad y migración a la ciudad. Los sombreros los compran en Pelileo, mientras que los ponchos los elaboran en la misma parroquia. Las mujeres de la parroquia utilizan "pichunchis" que son bayetas grandes, las cuales las sujetan con "tupos" y los anacos y "lliklas" que son anacos de una sola pieza.

\section{Mercados, espacios \\ de comercialización de alimentos}

Las ferias a las que acuden los habitantes de la parroquia son: feria local en la plaza parroquial, ferias de Riobamba, Guamote, Licto y Tzalarón. En estos lugares se comercializan pequeños volúmenes de productos agrícolas. Esporádicamente los habitantes de Flores acuden a la feria de Licto. Los principales centros de aprovisionamiento de alimentos e insumos agropecuarios son Riobamba, Guamote y Tzalarón. (Figura 15). 

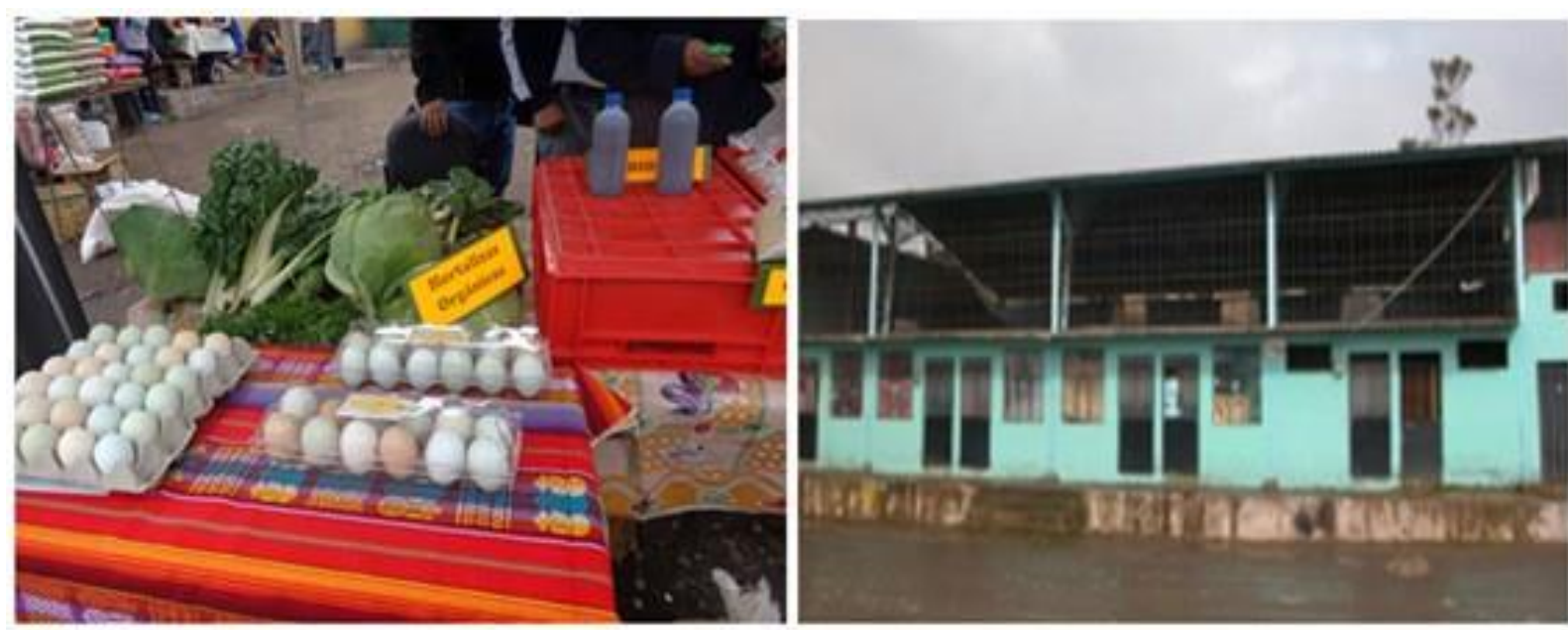

Figura 15. Feria en el mercado de la parroquia Flores. (Fotografía: GAD Parroquial de Flores, 2016).

\section{Lugares emblemáticos de la parroquia}

Los lugares más emblemáticos de esta localidad son: Cerro Puchi. Es el cerro más alto del sector. Camino del Inca (Kapak Ñan). Se encuentra en la comunidad de Rayopamba. Andenes o terrazas incásicas. El PDOT del GAD Parroquial, menciona que los andenes o terrazas incásicas en la actualidad, son utilizados para el cultivo de productos locales, principalmente de maíz.

\section{Medicina tradicional}

En la parroquia de Flores, se reporta la existencia de 24 personas que practican y ofertan los servicios de la medicina tradicional y ancestral, entre curanderos o yachaks, parteras y fregadores. Las principales prácticas de medicina tradicional son: limpias con cuy, huevo y plantas medicinales nativas (PDOT, 2015).

Para los tratamientos con este tipo de medicina, se emplean varias plantas nativas medicinales que se preparan de diferentes formas: aguas frescas, zumos, emplastos y son administradas por vía oral y tópica. A los niños y niñas con problemas entéricos (digestivos), les suministran aguas aromáticas de cola de caballo, trinitaria, ortiga negra o colada de avena con guayaba.

\section{Preparaciones culinarias}

\section{Gastronomía festiva}

La práctica culinaria está muy marcada en la parroquia de acuerdo a los productos que siembran y cosechan. La base de su alimentación se caracteriza por procedimientos, técnicas y métodos de cocción adquiridas de generación en generación, que han trascendido en el tiempo hasta la actualidad. Los más conocidos son: 


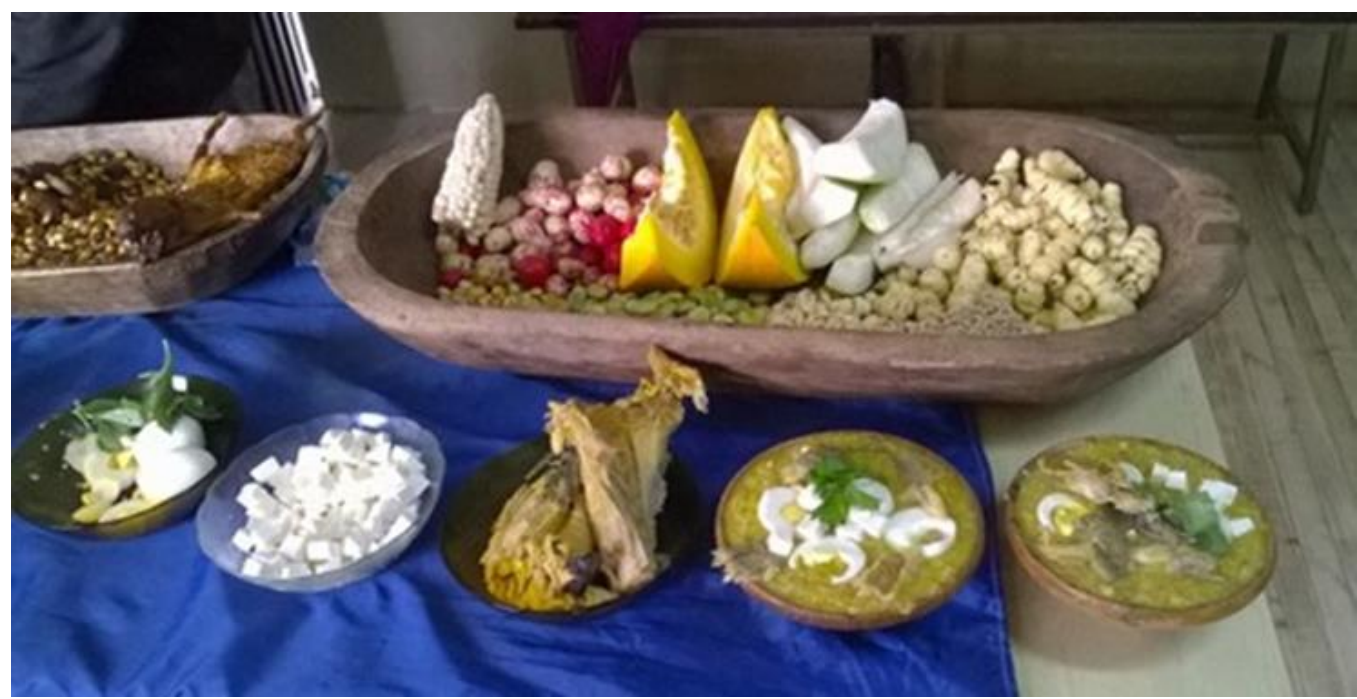

Figura 16. Mesa festiva, variedad de platos. (Fotografía: Javier Aucancela, 2016).

\section{Chicha de jora}

Se realiza en base al fermento del maíz en un proceso que dura 3 días. Esta debe estar lista para beber al inicio del Pawkar Raymi. El señor Anacleto Pucuna, morador de la parroquia Flores, indica: "Antes la chicha de jora la fermentaban en galones, haciendo remojar la jora (maíz) y dejándola en un lugar oscuro encima de paja, primero en sacos de cabuya y después se hacía en sacos plásticos, haciendo que crezca hasta una altura de medio metro y el retoño es el que se utiliza para sacar el germen, el que se muele en piedra de moler. Esto se cocinaba en ollas de barro y luego el afrecho se cernía en un harnero de metal."

Otros de los platos emblemáticos de esta parroquia son; Locro de cuy, Empanadas de maíz, Colada de máchica, Salsa de ají, Fritada de cerdo, Cuy con papas, Fanesca. En la investigación principal se encuentra cada una de las descripciones y recetarios de los platos antes mencionados.

\section{Artefactos y usos}

Para preparar sus alimentos, tenían un fogón (tantso rumi) que lo mantenían encendido todo el tiempo con estiércol seco de burro, paja de trigo y piedra; si el fogón se apagaba se acercaban a la casa de sus vecinos para pedir un poco de este material para volver a encender. El señor Anacleto Pucuna, morador de la parroquia Cacha, menciona: "La gente en su mayoría cocinaba en leña con paja de trigo, esta paja la guardaban en bloques llamados parvas, teniendo para usar todo el año, actualmente la gente también cocina con gas, según la posibilidad económica de las familias. Antes la casa era un solo cuarto, donde en un rincón se dormía, en otro se cocinaba y también guardaban a los cuyes".

Como parte de las manifestaciones culturales de cada comunidad, está latente su conocimiento en el uso de ingredientes con la ayuda de utensilios elaborados, tales como: cucharas de palo, ollas de barro, platos y tiestos, utilizados para el almacenaje de alimentos e imprescindibles para la cocción de la mayor parte de sus productos. Para ello, las ollas son "curadas" mediante conocimientos heredados de sus ancestros: se calienta la olla de barro y se vierte leche caliente para sellar totalmente los posibles orificios existentes en ella, con el fin de evitar filtraciones de líquidos. Otra forma, es 
frotar la olla caliente con cáscara de plátano verde varias veces hasta formar una capa impermeabilizante (Andino, 2012).

\section{Instrumentos de barro}

Ollas, pondos de varios tamaños y formas para facilitar la cocina, además tenían platos, compoteras y mates que les servían de mucha ayuda para las bebidas. Otros instrumentos que poseen son Cucharas de madera; Bateas; Cántaros; Tinajas; Tiestos; Piedras de moler.

\section{CONCLUSIONES}

En este estudio, no se ponen en discusión los mecanismos de poder en torno a la tradición, sino que se identificaron las prácticas que, de un modo u otro, perviven en las parroquias y que son referentes de las maneras de hacer las cosas en un lugar determinado. Si bien, en torno a la tradición, surge por ejemplo, la imposición de un imaginario colectivo sobredimensionando unos valores culturales y eliminando o subordinando a otros, el interés predominante de esta investigación fue compilar el saber existente en las personas, a nivel sincrónico.

Por otra parte, es importante destacar que la parroquia de Cacha se autodefine como Primera Parroquia Indígena del Ecuador, por lo que muchas de las prácticas y tradiciones que se mencionaron sobre esta parroquia, no están presentes en Flores, que tiene otros sentidos identitarios y muchos de sus elementos culturales así como su autodefinición, están relacionados con el mestizaje.

La preservación y difusión de las culturas indígenas son necesaria dentro del proceso de identidad en países como Ecuador, de esta manera se protege y se da a conocer las características que definen cada pueblo.

\section{REFERENCIAS}

Andino, D. (2012). Plan de desarrollo turístico para la parroquia Flores, cantón Riobamba, provincia Chimborazo. (Tesis de pregrado). Escuela Superior Politécnica de Chimborazo, Riobamba, Ecuador

Botero, F. y Endara, L. (2000). Mito, rito, símbolo. Lecturas antropológicas Quito, Ecuador: Instituto de Antropología Aplicada

Cepeda, F. (2003). Riobamba en el primer cuarto del siglo XX: ferrocarril, transformaciones urbanas $\mathrm{y}$ prácticas cotidianas. (Tesis de Maestría). Universidad Andina Simón Bolívar. Quito, Ecuador. Disponible en: http:// repositorio.uasb.edu.ec/bitstream/10644 /2355/1/T0205-MELA-Cepeda Riobamba.pdf

Coronel, R. (2006). Patrimonialismo, conflicto y poder en la reconstrucción de Riobamba, 1797 - 1822. Procesos, Revista Ecuatoriana de Historia, (24). Universidad Andina Simón Bolívar. Corporación Editora Nacional. Quito, Ecuador.

Contreras, J. y García, M. (2005). Alimentación y cultura. Perspectivas antropológicas. Barcelona, España

Costales, A. (1963). Fernando Daquilema, el último Guaminga. Quito, Ecuador: Instituto Ecuatoriano de Antropología y Geología, 142-193

Delgado, R. (2001). Comida y cultura: identidad y significado en el mundo contemporáneo. Estudios de Asia y África, 36 (1), enero-abril, pp. 83-108

Eliade, M. (1991). Mito y realidad. Barcelona, España: Editorial Labor, 9-28. Ganán, M. (2015). El tren turístico y su incidencia económica en el cantón Durán, parroquia Eloy Alfaro, provincia de Guayas: período 2012 - 2014. (Tesis de Pregrado). Universidad de Guayaquil. Guayaquil, Ecuador

Giove, R. (2015). Rituales de la vida, cotidianos y sagrados. Foros internacionales. Espiritualidad indígena. Sección 1. 39-45, Lima, Perú

Gobierno Autónomo Descentralizado Parroquial de Cacha. (2015). Plan de desarrollo y ordenamiento territorial 
Gobierno Autónomo Descentralizado Parroquial de Flores. (2015). Plan de desarrollo y ordenamiento territorial

González, M. (2015). La emergencia de lo ancestral. Una mirada sociológica. Espacio Abierto, 24 (3), 5-21

Guashpa, N. (2012). Propuesta para la implementación de un centro de interpretación cultural para el centro turístico Pucara Tambo, parroquia Cacha, cantón Riobamba, provincia de Chimborazo. (Tesis de pregrado). Escuela Superior Politécnica de Chimborazo, Riobamba, Ecuador

Madrazo, M. (2005). Algunas consideraciones en torno al significado de la tradición. Contribuciones desde Coatepec. Universidad Autónoma del Estado de México. (9), 115-132. Toluca, México

Paniagua, J. (1999). El proyecto de una ciudad ilustrada para América, el diseño de Riobamba (Ecuador). Polígonos, Revista de Geografía, 9. Universidad de León. León.

Sánchez, C. (2017). La comida como elemento configurador de la identidad en contextos migratorios. Apuntes sobre la experiencia de la población ecuatoriana en España. Anales del Museo Nacional de Antropología. Madrid. Disponible en: https://dialnet.unirioja.es/servlet/articul o? codigo $=6519972$

Sheib, A. y Oluoch, M. (2015). Fiesta e interculturalidad. El rito religioso en Licto. Quito, Ecuador: Corporación Editora Nacional. Universidad Andina Simón Bolívar

UNESCO. (2003). Aplicación de la Convención para la Salvaguardia del Patrimonio Cultural Inmaterial. Disponible en: https://ich.unesco.org/doc/ src/01853ES.pdf

UNESCO. (2003).Convención para la Salvaguardia del Patrimonio Cultural Inmaterial. París, 17 de octubre de 2003, Serie de Tratados de las Naciones Unidas, disponible en: http://portal.unesco.org/es/ev.phpURL ID $=17716 \&$ URL_DO=DO_TOPIC\&URL_SEC TION=201.html 